\title{
2540: Competition of the cotton bollworm (Helicoverpa armigera), corn earworm (Helicoverpa zea) and fall armyworm (Spodoptera frugiperda) on non-Bt corn
}

\author{
Wednesday, September 28, 2016 \\ 11:30 AM - 11:45 AM \\ P Convention Center - Room W225 B
}

Helicoverpa armigera, Spodoptera frugiperda and Helicoverpa zea (Boddie) (Lepidoptera: Noctuidae) are among the main pests of corn crop in Brazil and are characterized by having the same feeding guild during the reproductive stage of the crop. The intraguild competition of these noctuides was evaluated through the survival of each specie under field conditions, on non-Bt corn. Different competition scenarios, alternating the larval stadium of development, were carried out in corn ear. The survival of $H$. armigera in competition with the other species was significantly low compared to the control. H. zea showed high aggressive behavior and high rate of cannibalism. Their survival was reduced when it was competing against $S$. frugiperda in the same size. The survival of $S$. frugiperda remained high in the different scenarios of competition, being reduced when it was in a lower development than $H$. zea and $H$.

armigera. In general, $S$. frugiperda demonstrates advantage in the competition against $H$. zea and $H$. armigera on non-Bt corn.

doi: 10.1603/ICE.2016.114451

\section{Authors}

José P. G. F. Silva

Universidade Estadual Paulista

Edson L.L. Baldin

Universidade Estadual Paulista

Thomas E Hunt

University of Nebraska

Silvana V. Paula-Moraes

Embrapa Cerrados

\section{View Related Events}

Session: 413 Contributed Papers: Ecology and Population Dynamics: Interactions

Program: Paper (Oral) Presentations

Day: Wednesday, September 28, 2016 